\title{
Octahedron-based spatial bar structures - the form of large areas covers
}

\author{
Dominika Pilarska, \\ Faculty of Civil Engineering and Architecture, Opole University of Technology, Poland
}

\begin{abstract}
The large areas covers may be designed as the spatial dome constructions where the basis of their shaping are regular polyhedra. The paper presents eight new designed spatial bar structures as geodetic domes with a span of $50 \mathrm{~m}$. The basis of their shaping is the regular octahedron. This polyhedron has not been recognized in detail as the basis for geodesic domes designing. Using second method of the division of the initial equilateral triangle proposed by professor Fuliński, bar domes generated from 2904-hedron, 3456-hedron, 4056-hedron, 4704-hedron, 5400-hedron, 6144-hedron, 6936-hedron and 7776-hedron were obtained. The designed eight bar structures were subjected to thorough geometric and static analysis showing the behaviour of the geodesic bar domes generated according to the presented in the paper method of the division of original face of regular octahedron. Own formulas were developed to determine the number of nodes and bars. The designed eight bar systems in the form of geodesic domes, which the basis of shaping is regular octahedron can be used as the covers of large areas without the necessity of the internal supports usage.
\end{abstract}

\section{Introduction}

Increasing expectations for covers of large areas create opportunities for shaping innovative forms of structural systems. Architectural and design requirements cause the formation of various forms of such constructions. The main objectives of dome constructions are to aim to the weight of the structure optimization as well as to obtain a cover with huge possibilities of large area usage thanks to the lack of internal supports. The usage of steel in such kinds of construction systems is reflected in a relatively small own weight of the constructions. The other advantages of the spatial bar structures are the usage of straight bars, high rigidity of the structure, ease of shaping, relatively easy assembly. The public facilities covers such as fair halls, show halls, sports and recreational facilities, railway stations as well as their construction parts, are designed, inter alia, as domed construction where the basis of their shaping are regular polyhedra. Their grids can reach a span of more than 100 meters. However, the most common types of such structures, that cover the public buildings, have a diameter of $50-60 \mathrm{~m}$. Figs 1 and 2 present examples of covers in the form of geodetic domes.

\footnotetext{
${ }^{*}$ Corresponding author: $\underline{\text { d.pilarska@po.opole.pl }}$
} 


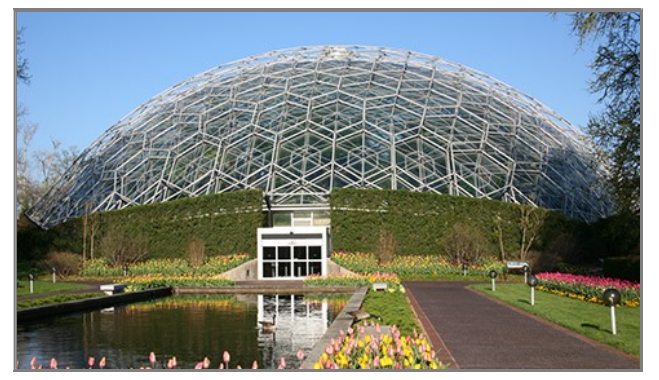

Fig. 1. Climatron, a geodesic dome greenhouse designed by R. Buckminster Fuller, Missouri Botanical Garden, St Louis USA (1960).

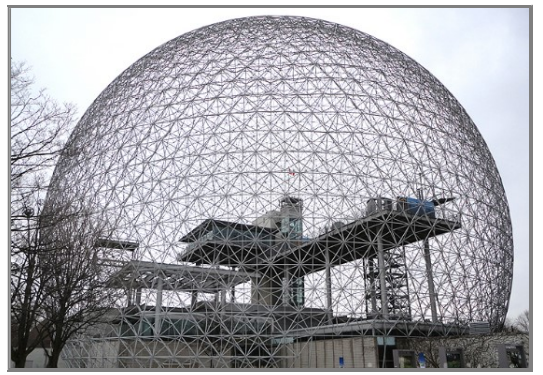

Fig. 2. Geodesic dome, Montreal Expo, diameter 76 m, covered with acrylic (Fuller, 1967).

Fuller geodesic domes [1] in the second half of the twentieth century were constructed on the basis of 20-hedron and 12-hedron because of a large number of bars of equal length and a small number of groups of bars of different lengths. Domes based on 20-hedron and 12-hedron were analyzed theoretically, for example, by T. Tarnai [2], J. Fuliński [3] and J. Rębielak [4]. Another more original approach proposed by J.B. Obrębski involves dividing a sphere by intersecting great circles [5]. Fuller's ideas were continued by a number of distinguished architects, for instance Z. Makowski [6].

A literature survey shows that the geometric problems and static analysis related to the other regular polyhedra (based on 8-hedron, 6-hedron and 4-hedron) have not been studied. The regular octahedron, which faces constitute equilateral triangles can be used for geodesic domes shaping. By the division of its original faces into smaller and smaller, we obtain a grid of covering which density is determined by the needs of the designed construction and the expectations of architectural solutions.

\section{Shaping of the designed octahedron - based spatial bar structures}

The paper presents eight designed one-layered spatial bar structures as geodesic domes with a span of $50 \mathrm{~m}$. The basis of their shaping is the regular octahedron. Its original equilateral triangles were divided into smaller triangular elements, using one of three methods proposed by professor J. Fuliński. The first method leads to the division of each edge of the initial triangle into $n$ parts and to draw three families of lines parallel to each of the edge. In the second method, after dividing edges into $n$ parts, three families of parallel lines are drawing to the lines of heights. The third method is also connected with the division of edges into $n$ parts, where the further families of parallel lines are drawing to line passing through the vertex and one point laying on the opposite edge (not necessarily the first one, but also not the middle one) $[3,7,8]$. The first method has already been recognized by the author in earlier considerations $[9,10]$. This paper is concentrated on the second method of 
the division. Fig 3 shows the applied in the paper method of the division on the example of dividing the edges of the original face of the regular octahedron into 2, 4, 6 and 8 parts.

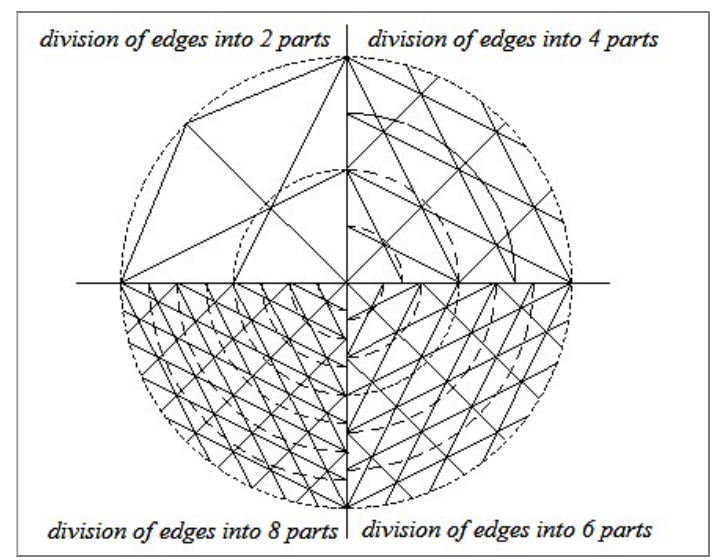

Fig. 3. The applied method of the division of edges of the original face of the regular octahedron on the example of division into 2, 4, 6 and 8 parts.

Using the above presented method of the division, following structures were shaped:

- 2904-hedron - division of the original edges into 22 parts (structure number 1),

- 3456-hedron - division of the original edges into 24 parts (structure number 2),

- 4056-hedron - division of the original edges into 26 parts (structure number 3),

- 4704-hedron - division of the original edges into 28 parts (structure number 4),

- 5400-hedron - division of the original edges into 30 parts (structure number 5),

- 6144-hedron - division of the original edges into 32 parts (structure number 6),

- 6936-hedron - division of the original edges into 34 parts (structure number 7),

- 7776-hedron - division of the original edges into 36 parts (structure number 8).

The structures were modelled in Autodesk Robot Structural Analysis program. Examples of two bar domes are presented in Fig 4.

a) 2904-hedron

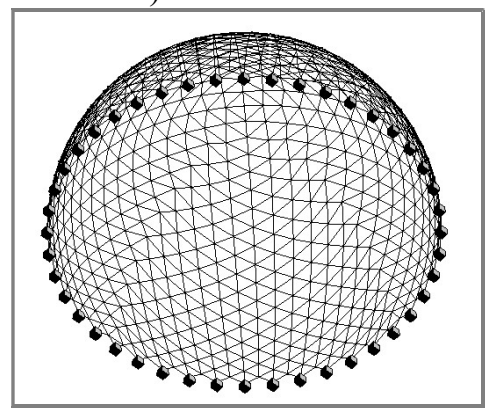

b) 7776-hedron

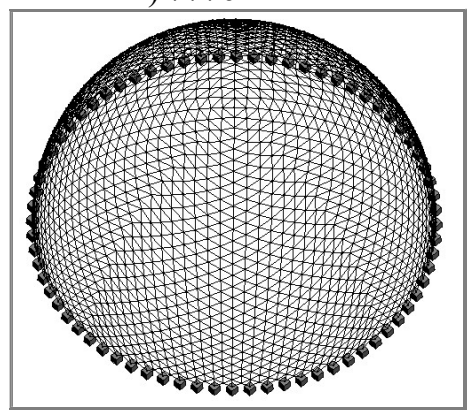

Fig. 4. The geodesic dome with the diameter of $50 \mathrm{~m}$, formed of: a) 2904-hedron, the division of original edges of the regular octahedron into 22 equal parts - structure number 1 ; b) 7776-hedron, the division of original edges of the regular octahedron into 36 equal parts - structure number 8 .

\section{Geometric analysis of the designed octahedron - based spatial bar structures}

Eight designed bar structures were subjected to a geometric study, taking into account the following geometric parameters: 
- the number of nodes, bars, supports,

- groups of bars with different lengths,

- minimum and maximum bar lengths.

With the increase in the degree of division of the octahedral meshes, the number of nodes and bars increases. The difference of this increase compared to the previous considered dome rises by 12 in number of nodes and by 36 in number of bars. The detailed analysis of the considered parameters is shown in Table 1.

Table 1. Consideration regarding the number of nodes and number of bars in developed bar domes.

\begin{tabular}{|c|c|c|c|c|c|c|c|}
\hline No & designed bar dome & $\begin{array}{c}\text { number of } \\
\text { nodes }\end{array}$ & $\begin{array}{c}\text { difference } \\
\text { between } \\
\text { number } \\
\text { of nodes }\end{array}$ & $\begin{array}{c}\text { increase } \\
\text { in difference } \\
\text { between } \\
\text { number of nodes }\end{array}$ & $\begin{array}{c}\text { number of } \\
\text { bars }\end{array}$ & $\begin{array}{c}\text { difference } \\
\text { between } \\
\text { number } \\
\text { of bars }\end{array}$ & $\begin{array}{c}\text { increase } \\
\text { in difference } \\
\text { between } \\
\text { number of bars }\end{array}$ \\
\hline 1 & 2904-hedron & $749^{-}$ & & & $215 \overline{6}$ & & \\
\hline 2 & 3456-hedron & 889 & & 12 & 2568 & & 36 \\
\hline 3 & 4056-hedron & $104 \overline{1}$ & & 12 & $301 \overline{6}$ & & 36 \\
\hline 4 & 4704-hedron & $1205^{-}$ & & 12 & $3500^{-}$ & & 36 \\
\hline 5 & 5400-hedron & $138 \overline{1}$ & & 12 & $402 \overline{0}$ & & 36 \\
\hline 6 & 6144-hedron & $1569^{-}$ & & 12 & $4576^{-}$ & & 36 \\
\hline 7 & 6936-hedron & 1769 & & 12 & 5168 & & 36 \\
\hline 8 & 7776-hedron & 1981 & & & 5796 & & \\
\hline
\end{tabular}

The detailed analysis of the number of nodes as well as number of bars of eight designed structures allowed to develop own formulas for their determination for domes not involved in this study (i.e. for domes with smaller or greater degree of approximation, formed according to the analyzed second method of the division of the original octahedron face).

The number of nodes in a bar dome generated according to the presented in this paper method of the division of the original face of the regular octahedron can be determined as follows:

$$
N_{n}=p+8+\left(N^{*} 12\right)
$$

where:

$\mathrm{N}_{\mathrm{n}}$ - number of nodes

$\mathrm{p}$ - the result of the previous polyhedron

$\mathrm{N}$ - subsequent natural number

The number of bars in these types of bar structures can be calculated using the formula:

$$
N_{b}=p+16+\left(N^{*} 36\right)
$$

where:

$\mathrm{N}_{\mathrm{b}}$ - number of bars

$\mathrm{p}$ - the result of the previous polyhedron

$\mathrm{N}$ - subsequent natural number 
Using the developed formulas (1) and (2), Fig 5 shows the graphs of the number of nodes and the number of bars for eight analyzed structures as well as for others, with a smaller or greater approximation degree.

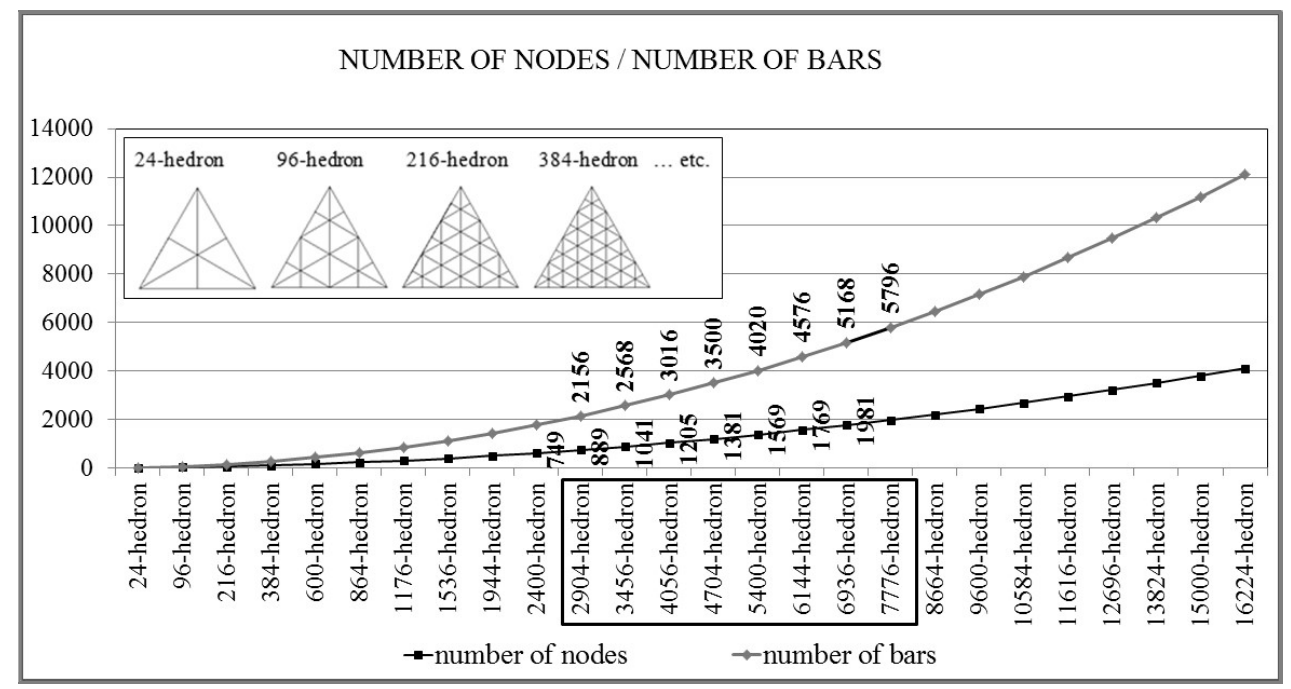

Fig. 5. The number of nodes and bars for the structures generated according to the same division of the regular octahedron original face.

Increase in the degree of bar density of analyzed structures also increases the number of supports. This increase is by 4 in relation to the previous designed dome. It is caused by the additional division in each of the four initial edges of the octahedron base. The data are tabulated in Table 2 .

Table 2. The number of supports in developed bar domes.

\begin{tabular}{|c|c|c|c|}
\hline 2904-hedron & 3456-hedron & 4056 -hedron & 4704-hedron \\
\hline 44 & 48 & 52 & 56 \\
\hline 5400 -hedron & 6144 -hedron & 6936 -hedron & 7776 -hedron \\
\hline 60 & 64 & 68 & 72 \\
\hline
\end{tabular}

Further analyzed geometric parameters refer to groups containing bars of the same lengths. The number of these groups occurring in the individual structures was determined. The average number of bars in one group was indicated. The greater bar density does not cause the increase of the number of groups of bars with different lengths. It oscillates around 120-130 in each shaped bar system. Domes characterized by the greater approximation of the sphere have the greater average number of elements in one group. This is because they are formed from more bars, but they are listed in the comparable number of groups. For example, 2904-hedron dome has 2156 bars, 129 groups of bars of different lengths, so on average there are 17 bars of the same length in one group. Whereas, 7776-hedron dome has 5796 bars which are classified into 118 groups. In this case, on average, there are 49 bars in one group. The details concerning groups of bars with different length are presented in Fig 6. 


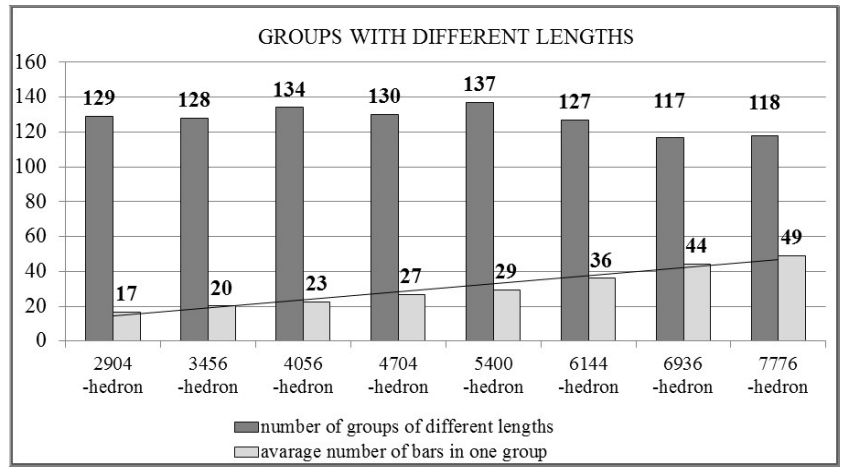

Fig. 6. The number of groups of bars of different length and the average number of bars in one group.

Among all the bar elements of a given dome, the bars with the minimum and the maximum lengths were separated. They are presented in Fig 7. With the increase in the bar density of the structure, their lengths, both minimum and maximum, decrease by about $6-8 \%$ compared to the previous system.

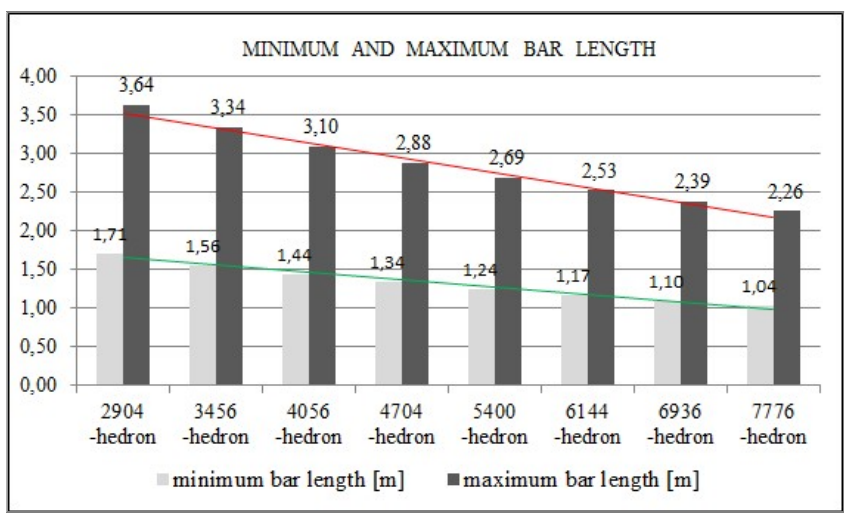

Fig. 7. Minimum and maximum bar length in developed bar domes.

The difference between maximum and minimum lengths of bars in a given dome also decreases with the increase in approximation of the structure surface. For instance, the difference between maximum and minimum lengths of bars in the 2904-hedron dome is $1,93 \mathrm{~m}$, while it is $1,22 \mathrm{~m}$ in the 7776-hedron dome. The total length of all bars in the developed bar structures increase by about $500 \mathrm{~m}$ compared to the previous dome. It is shown in Fig 8.

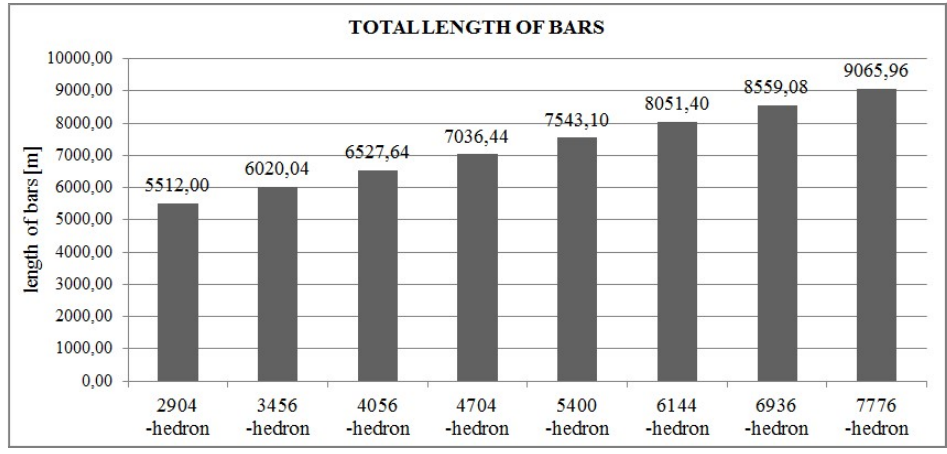

Fig. 8. Total length of bars in the developed bar domes. 


\section{Static analysis of the designed octahedron - based spatial bar structures}

\subsection{Assumptions}

The static analysis of the developed eight bar domes was carried out in the Autodesk Robot Structural Analysis program. The following loads were taken into account: the fixed load, i.e. own weight of construction and weight of cover constituting glass panes with a weight of $0.6 \mathrm{kN} / \mathrm{m}^{2}$, as well as variable load, i.e. snow and wind for the first climate zone. From the presented interactions, the following load combinations were created: combination no 1 containing fixed influences as well as leading variable influences of the wind and accompanying variable influences of the snow, combination no 2 consisting of fixed influences as well as leading variable influences of the snow and accompanying variable influences of the wind, combination no 3 including fixed influences as well as leading variable influences of the wind.

S235 steel with a yield strength $235 \mathrm{MPa}$ was adopted. A round tube cross-section for all bars of the analyzed domes were assumed. Supports were given as restraints, nodes were assumed as articulated.

\subsection{Dimensioning}

First, based on topological-geometric parameters, all domes were modelled. The bars of structures were classified into 4 groups, taking into account a stress distribution in individual bars at the load of own weight. Elements in each group were assigned a cross section of the round tube, taking into account the usage of the most strained bars in the group at the level of $80-90 \%$. List of individual groups of bars in a given dome together with the assigned cross section and the coefficient of bar tension is presented in Table 3 .

Table 3. The division into groups of bars with assigned cross-sections and coefficient of bar tension in developed bar domes

\begin{tabular}{|c|c|c|c|c|c|c|c|c|c|}
\hline \multicolumn{2}{|c|}{$\begin{array}{l}\text { DEVELOPED } \\
\text { BAR DOME }\end{array}$} & \multirow{2}{*}{ 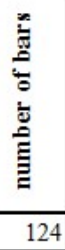 } & \multirow{2}{*}{ 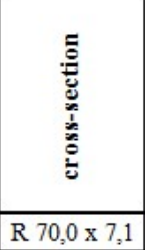 } & \multirow{2}{*}{ 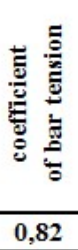 } & \multicolumn{2}{|c|}{$\begin{array}{l}\text { DEVELOPED } \\
\text { BAR DOME }\end{array}$} & \multirow{2}{*}{ 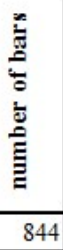 } & \multirow{2}{*}{ 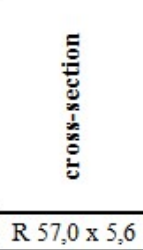 } & \multirow{2}{*}{ 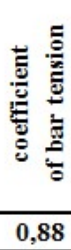 } \\
\hline \multirow{8}{*}{ 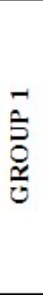 } & 2904-hedron & & & & \multirow{8}{*}{$\begin{array}{l}m \\
\vdots \\
0 \\
\underline{y} \\
0\end{array}$} & 2904-hedron & & & \\
\hline & 3456-hedron & 100 & R $70,0 \times 7,1$ & 0,85 & & 3456-hedron & 976 & $\mathrm{R} 57,0 \times 8,0$ & 0,86 \\
\hline & 4056-hedron & 136 & R $70,0 \times 8,0$ & 0,89 & & 4056-hedron & 1196 & R $57,0 \times 8,8$ & 0,88 \\
\hline & 4704-hedron & 136 & R $70,0 \times 8,0$ & 0,90 & & 4704-hedron & 1372 & $\mathrm{R} 57,0 \times 8,0$ & 0,90 \\
\hline & 5400-hedron & 188 & R $60,3 \times 8,8$ & 0,89 & & 5400-hedron & 1622 & $\mathrm{R} 54,0 \times 8,0$ & 0,85 \\
\hline & 6144-hedron & 200 & R $70,0 \times 8,0$ & 0,88 & & 6144-hedron & 1844 & R $57,0 \times 8,0$ & 0,87 \\
\hline & 6936-hedron & 188 & R $70,0 \times 8,8$ & 0,84 & & 6936-hedron & 2048 & R $57,0 \times 8,0$ & 0,84 \\
\hline & 7776-hedron & 164 & R $70,0 \times 8,8$ & 0,86 & & 7776-hedron & 2311 & R $57,0 \times 8,8$ & 0,88 \\
\hline \multirow{8}{*}{ 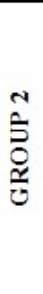 } & 2904-hedron & 748 & $\mathrm{R} 63,5 \times 8,0$ & 0,88 & \multirow{8}{*}{ 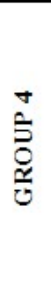 } & 2904-hedron & 440 & R $51,0 \times 3,2$ & 0,80 \\
\hline & 3456-hedron & 868 & $\mathrm{R} 63,5 \times 7,1$ & 0,90 & & 3456-hedron & 624 & $\mathrm{R} 48,3 \times 4,5$ & 0,87 \\
\hline & 4056-hedron & 1036 & R $63,5 \times 8,8$ & 0,90 & & 4056-hedron & 648 & $\mathrm{R} 44,5 \times 5,6$ & 0,87 \\
\hline & 4704-hedron & 1164 & R $63,5 \times 8,8$ & 0,88 & & 4704-hedron & 828 & $\mathrm{R} 44,5 \times 6,3$ & 0,84 \\
\hline & 5400-hedron & 1372 & R $60,3 \times 8,0$ & 0,87 & & 5400-hedron & 838 & $\mathrm{R} 51,0 \times 5,0$ & 0,86 \\
\hline & 6144-hedron & 1552 & $\mathrm{R} 63,5 \times 8,0$ & 0,90 & & 6144-hedron & 980 & $\mathrm{R} 48,3 \times 6,3$ & 0,89 \\
\hline & 6936-hedron & 1784 & $\mathrm{R} 63,5 \times 8,8$ & 0,84 & & 6936-hedron & 1148 & R $51,0 \times 6,3$ & 0,90 \\
\hline & 7776-hedron & 1972 & R $63,5 \times 8,0$ & 0,89 & & 7776-hedron & 1349 & R $54,0 \times 6,3$ & 0,89 \\
\hline
\end{tabular}


Each cross section of the bars in a given group was analyzed in terms of its weight and finally the total weight of each designed system was obtained. Domes with a greater density of bars are characterized by a greater total weight (Fig 9).

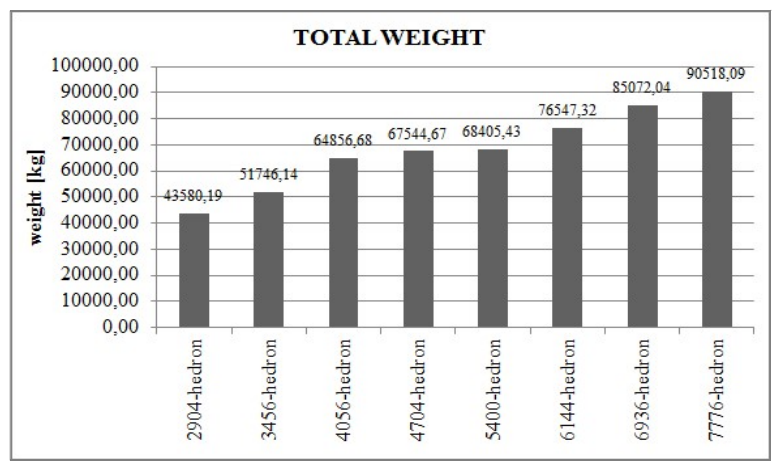

Fig. 9. Total weight of the designed bar domes.

\subsection{Static analysis results}

The designed bar domes were subjected to the analysis of linear statics, including comparison of: extreme axial forces occurring in bars, maximum vertical and horizontal displacements of nodes and maximum and minimum values of stresses.

Extreme values of axial forces (tensile and compressive) occur in the case of the load combination taking into account the impact of fixed influences as well as leading variable influences of the wind and accompanying variable influences of the snow. These values are presented in Fig 10.

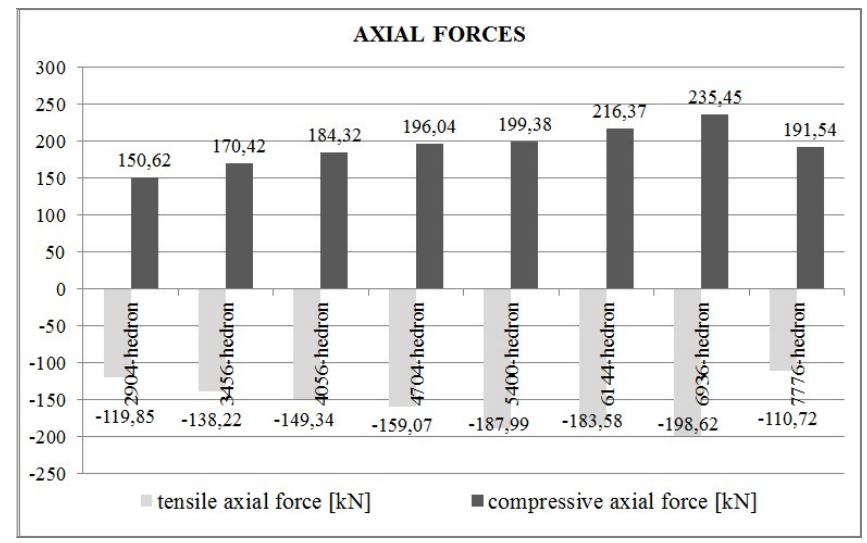

Fig. 10. Extreme values of tensile and compressive axial forces occurring in the most disadvantaged load combination in developed bar domes.

Maximum vertical displacements of nodes occur in the case of the load combination taking into account the impact of fixed influences as well as leading variable influences of the snow and accompanying variable influences of the wind. Maximum horizontal displacements of nodes was noted taking into account fixed influences as well as leading variable influences of the wind and accompanying variable influences of the snow. The obtained results of the maximum displacements are presented in Fig 11. Fig 12 shows distribution of vertical displacements of nodes for the exemplary bar dome formed of 4056hedron. 


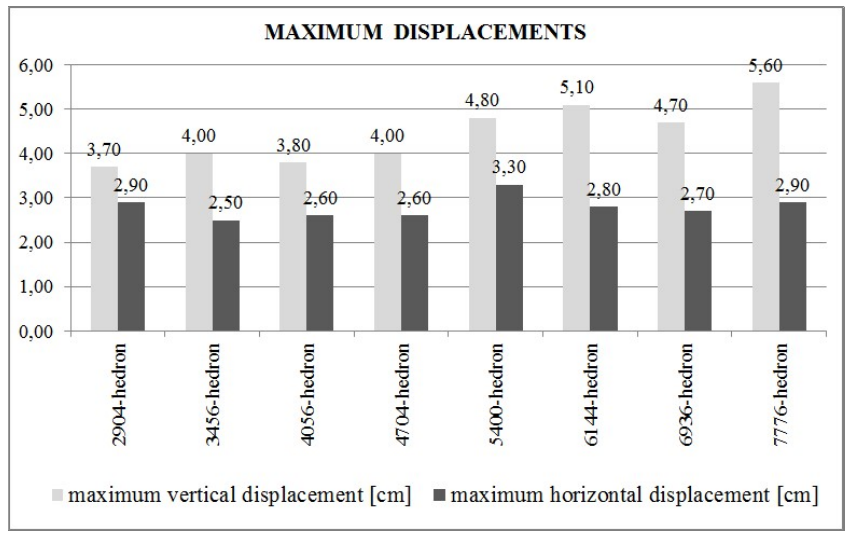

Fig. 11. Maximum values of vertical and horizontal displacements of nodes occurring in the most disadvantaged load combination in developed bar domes.

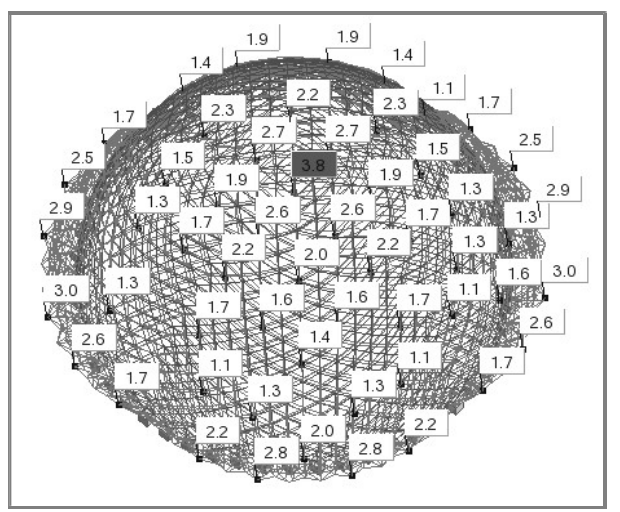

Fig. 12. Distribution of vertical displacements of nodes in the most disadvantaged load combination in the exemplary bar dome formed of 4056-hedron.

Extreme values of normal stresses occur in the designed domes loaded by the fixed influences as well as leading variable influences of the wind and accompanying variable influences of the snow (Fig 13).

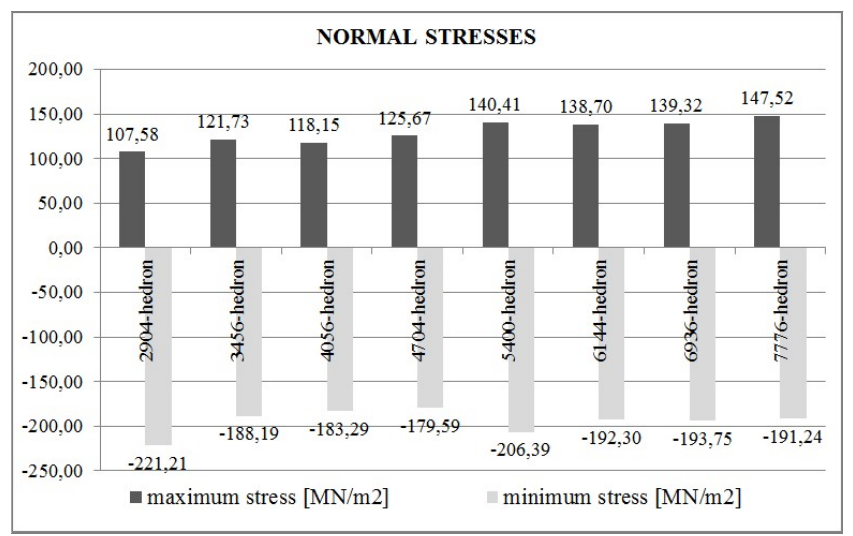

Fig. 13. Normal stresses occurring in the most disadvantaged load combination in developed bar domes. 


\section{Summary}

The paper presents eight bar structures shaped on the basis of the second method of the division of the original face of regular octahedron, proposed by professor J. Fuliński. Structures with a diameter of $50 \mathrm{~m}$, varying in degree of bar density, were designed. Eight new developed domes were subjected the detail geometric analysis, including: number of nodes, bars and supports, groups of bars of different lengths, average number of elements occurring in them, maximum and minimum lengths of bars. Algorithms and formulas were developed to get quickly information on geometric parameters of domes formed on the basis of the regular octahedron, according to professor J.Fuliński method applied, but not covered by this study. The structures were modelled in Autodesk Robot Structural Analysis program, and their elements were arranged into four groups. Bars in each group were dimensioned, taking into account both the usage of the most strained bars in the group at the level of $80-90 \%$. The developed domes were subjected to the linear static analysis, the aim of which was to present the behavior of the structures formed according to the presented in the paper method of the division of the original faces of the regular octahedron. The analysis covered extreme values of axial forces, vertical and horizontal displacements of nodes, as well as maximum and minimum values of normal stresses, taking into account the most disadvantaged case of load combinations.

The developed eight bar systems in the form of geodesic domes, which the basis is regular octahedron can be used as the covers of large areas without the necessity of the internal supports usage.

\section{References}

1. B. R. Fuller, Geodesic Tent. United States Patent Office, patent 2, 914, 074, Nov. 24/1959

2. T. Tarnai, Spherical Grids of Triangular Network, Acta Technica Academiae Hungaricae. Tomus 76, 3-4 (1974)

3. J. Fuliński, Geometria kratownic powierzchniowych, Prace Wrocławskiego Towarzystwa Naukowego. Seria B; 178/1973

4. J. Rębielak, Struktury przestrzenne o dużych rozpiętościach, PNIAiU.PWr., Nr 27, Seria: Monografie Nr 15. Wyd. P.Wr. (1992)

5. J. B. Obrębski, Unidom-space bar system, Local Seminar of IASS Polish Charter; XII LSCE 2006; Warszawa (2006)

6. Z. S. Makowski, Raümliche Tragwerke aus Stahl, Verlag Stahleisen m.b.H. Düsseldorf (1963)

7. J. Z. Mirski, Siatki powstałe z przekształceń 8-ścianu foremnego, Zeszyty Naukowe Akademii Rolniczej we Wrocławiu. Melioracja XLI; nr 212/1992, s.27-39 (1992)

8. Z. Kowal, J. Z. Mirski, Parametry geometryczne wybranej rodziny dwuwarstwowych kopuł prętowych, III Konferencja Naukowa: Konstrukcje Szkieletowe w Budownictwie Ogólnym

9. D. Pilarska, Prętowe kopuły geodezyjne - propozycje przekryć dużych powierzchni, 62 Konferencja Naukowa Komitetu Inżynierii Lądowej i Wodnej PAN i Komitetu Nauki PZITB, Journal of Civil Engineering, Environment and Architecture, t.XXXIII, z. 63 (1/I/16), str.447-454 (2016)

10. D. Pilarska, Covers of large areas in the form of octahedron - based spatial bar structures, XXIII Lightweight Structures in Civil Engineering, Bydgoszcz 2017r., str.41-46 (2017) 